\title{
Effects of Prenatal and Neonatal Exposure to Bisphenol A on the Development of the Central Nervous System
}

\author{
Keisuke Mizuo, Minoru Narita*, Kazuya Miyagawa, and Tsutomu SuzukI* \\ Department of Toxicology, Hoshi University School of Pharmacy and Pharmaceutical Sciences, Tokyo 142-8501, Japan
}

(Received April 7, 2010; Accepted April 27, 2010)

\begin{abstract}
Bisphenol A (BPA) is one of the most common endocrine disrupters. In the last decade, the number of studies concerning the effects of chronic treatment with BPA on the development of the central nervous system (CNS) has increased. However, little is known about the effects of chronic exposure to BPA on higher brain functions such as memory or psychomotor functions. Here, we report our following findings: (1) Prenatal and neonatal exposure to BPA enhances psychostimulant-induced rewarding effects, results in the up- or downregulation of dopamine receptors, causes memory impairment, and decreases choline acetyltransferase (ChAT) activity. (2) BPA activates astrocytes in vivo and in vitro. These findings suggest that prenatal and neonatal exposure to BPA affects the development of the CNS.
\end{abstract}

Keywords: Bisphenol A, Rewarding effect, Memory impairment, Astrocyte

\section{INTRODUCTION}

Bisphenol A (BPA), one of the most common environmental endocrine disrupters, has been extensively evaluated for toxicity, including developmental and reproductive toxicity and carcinogenicity, through various tests in rodents. This compound is a monomer of polycarbonate plastics and is used for manufacturing epoxy resins (used for lining food and beverage cans) and dental sealants. Incomplete polymerization of the monomer causes BPA to easily leach out from the polycarbonate plastics and epoxy resins during heating of the cans or during contact with basic or acidic substances. There is increasing evidence that prenatal exposure to BPA affects the development of living animals. It has been reported that administration of BPA to pregnant mice at a dose that is within the range of the environmental levels that humans are typically exposed to causes remarkable changes in the postnatal growth rate and leads to early onset of puberty in these mice (Howdeshell et al., 1999). Recently, it has been reported that prenatal exposure to BPA disrupts the brain sexual differ-

\footnotetext{
${ }^{*}$ Corresponding authors

Tel: +81-3-5498-5628 Fax: +81-3-5498-5628

E-mail: narita@hoshi.ac.jp (M. Narita)

E-mail: suzuki@hoshi.ac.jp (T. Suzuki)
}

entiation and sociosexual behaviors in rats (Kubo et al., 2001; Farabollini et al., 2002). In this review article, we summarize the effects of prenatal exposure to BPA on the central nervous system (CNS).

\section{EFFECTS OF PRENATAL EXPOSURE TO BPA ON THE CENTRAL DOPAMINERGIC SYSTEM}

\section{Effects of BPA on dopamine-related behaviors}

Dopamine, which is the major catecholamine in the CNS, is involved in the regulation of various functions, including locomotor activity, emotional processes, and neuroendocrine secretion. Dopaminergic neurons are localized mainly in the substantia nigra pars compacta, ventral tegmental area (VTA), and hypothalamus. These neurons form 3 main pathways: the nigrostriatal, mesolimbic, and tuberoinfundibular pathways. It is widely known that imbalances in dopamine transmission in the mesolimbic pathway, which comprises neurons projecting from the VTA mainly to the nucleus accumbens (NAcc.), results in psychiatric disorders such as schizophrenia and drug dependence (Sigmundson, 1994; Bardo, 1998). Drug dependence is a pathological behavior characterized by compulsive drug seeking and drug ingestion despite severe adverse consequences. The place conditioning para- 
digm is the most frequently used method to evaluate the motivational properties of drugs; further, when compared to the self-administration paradigm, this method has been reported to be frequently applied (Suzuki, 1996; Narita et al., 2001).

We reported that prenatal exposure to BPA induced hypersensitivity reactions in response to psychostimulants such as methamphetamine or morphine (Fig. 1A, B) (Suzuki et al., 2003; Mizuo et al., 2004a). The enhance- ment of psychostimulant-induced rewarding effects after prenatal exposure to BPA was completely reversed by pretreatment with a dopamine $\mathrm{D}_{1}$ receptor antagonist, $\mathrm{SCH} 23390$ (Suzuki et al., 2003). We also showed that prenatal exposure to BPA resulted in upregulation of dopamine $D_{1}$ receptor signaling (Fig. 1C) (Suzuki et al., 2003). Moreover, we found that prenatal and neonatal exposure to BPA decreased the number of dopamine $D_{3}$ receptors and attenuated dopamine $D_{3}$ receptor-mediated G-protein activation
(A)

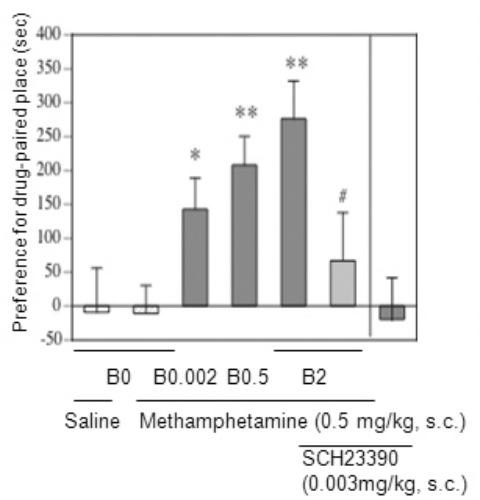

(C)

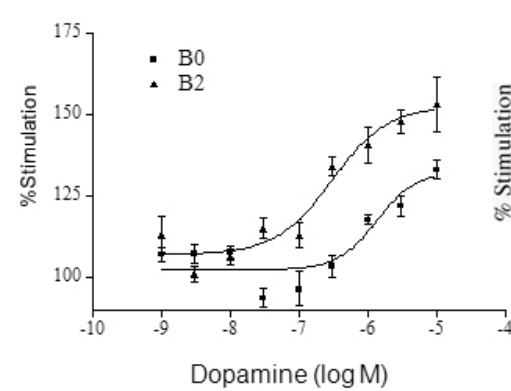

(B)

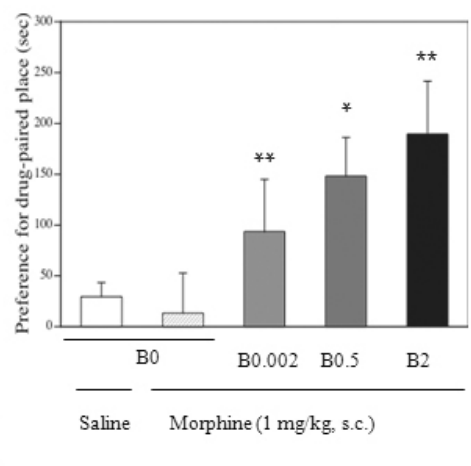

(D)

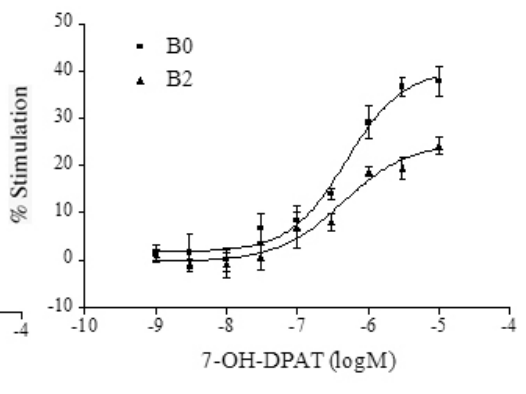

Fig. 1. Effects of prenatal and neonatal exposure to bisphenol $A$ (BPA) on the rewarding effects of abused drugs in mice. (A) Effects of BPA $(0.002-2 \mathrm{mg} / \mathrm{g}$ of food: B0.002-B2) on methamphetamine $(0.5 \mathrm{mg} / \mathrm{kg}$, s.c.)-induced place preference. Methamphetamine-induced place preference or place aversion was not observed in mice that did not receive BPA exposure (BPA-untreated group; hatched bar). Mice belonging to the BPA-treated group (filled bar) showed a significant place preference when methamphetamine was administered at the abovementioned dose $\left({ }^{*} p<0.05,{ }^{* *} p<0.01\right.$ vs. BPA-untreated group). Each column presents the mean \pm standard error of mean (SEM) scores of place preference of 6-10 mice. (B) Effects of BPA (0.002-2 mg/g of food: B0.002-B2) on morphine (1 mg/kg, S.c.)-induced place preference. Mice in the BPA-untreated group (hatched bar) did not show any morphine-induced place preference or place aversion. Mice in the BPA-treated group (filled bar) showed a significant morphine-induced place preference when they were administered the abovementioned dose of morphine $\left({ }^{*} p<0.05,{ }^{* *} p<0.01\right.$ vs. BPA-non treated group). Each column presents the mean \pm SEM scores of place preference of 6-10 mice. (C) Comparison of the dopamine-induced [ $\left.{ }^{35} \mathrm{~S}\right]$ Guanosine-5'-o-(3thiotriphosphate) (GTP $\gamma$ S) binding to membranes of the limbic forebrain between control (B0: square) and BPA-treated (B2: triangle) mice. The membranes were incubated with $\left.{ }^{35} \mathrm{~S}\right] \mathrm{GTP} \gamma \mathrm{S}(50 \mathrm{pM})$, GDP $(30 \mu \mathrm{M})$, and dopamine $\left(10^{-9}-10^{-5} \mathrm{M}\right)$. (D) Comparison of dopamine $\mathrm{D}_{3}$ receptor agonist 7-OH-DPAT-induced [ $\left.{ }^{35} \mathrm{~S}\right] \mathrm{GTP} \gamma \mathrm{S}$ binding to membranes of the limbic forebrain between the B0 (square) and B2 (triangle) mice. The membranes were incubated with $\left[{ }^{35} \mathrm{~S}\right] \mathrm{GTP} \gamma \mathrm{S}(50 \mathrm{pM})$, GDP $(30 \mu \mathrm{M})$, and $7-\mathrm{OH}-\mathrm{DPAT}\left(10^{-9}-10^{-5} \mathrm{M}\right)$. The values are expressed as percentage increase of the value obtained for B0 mice. The data are expressed as mean \pm SEM of 3 independent samples. [Panel (A) and (C) are modified and reproduced from Suzuki et al., Neuroscience 117, 639-644. Copyright 2003, with permission from Elsevier. Panel (B) is modified and reproduced from Mizuo et al., Neurosci Lett 356, 95-98. Copyright 2004, with permission from Elsevier. Panel (D) is reproduced from Mizuo et al., Addict Biol. 9, 19-25. Copyright 2004, with permission from Wiley-Blackwell.] 
through the preferential dopamine $D_{3}$ receptor agonist 7-hydroxy-N, N-di-n-propyl-2-aminotetralin (7-OH-DPAT) in the mouse limbic forebrain (Fig. 1D) (Mizuo et al., 2004c). The dopamine $D_{3}$ receptor is widely distributed in the NAcc., the terminal site of the mesolimbic dopaminergic system (Sokoloff et al., 1990). The selective expression of the dopamine $D_{3}$ receptor in the limbic system has generated remarkable interest in this receptor as a potential mediator of some of the psychoactive effects of drugs on dopamine neurotransmission (Koob, 1992; Devoto et al., 1995; Levant, 1997; Koeltzow et al., 1998). In addition, we have already reported that deletion of the central dopamine $D_{3}$ receptor gene results in the enhancement of postsynaptic dopamine $D_{1} / D_{2}$ receptor-mediated signaling, which in turn leads to the enhancement of morphine-induced rewarding effects and hyperlocomotion (Narita et al., 2003; Mizuo et al., 2004b). Our findings suggest that alteration in the functions of the dopaminergic system by prenatal and neonatal exposure to BPA is attributable to changes in the functions of the dopamine $D_{3}$ receptor. Many previous findings suggest that prenatal exposure to BPA affects the development of the monoaminergic system. Matsuda et al. (2010) reported that prenatal ex- posure to BPA alters the concentration of monoamines in the brain. In addition, Tian et al. (2010) showed that prenatal and neonatal exposure to BPA increases dopamine $D_{2}$ receptor binding in the caudate putamen of mice. These results strongly support our findings that prenatal exposure to BPA affects dopamine-related behaviors.

\section{Effects of low doses and importance of the duration of exposure to BPA}

It should be mentioned that the blood level of BPA in 2 $\mathrm{mg} / \mathrm{g}$ of food group (approximately $10 \mathrm{ng} / \mathrm{ml}$, data not shown) is considered to be more than 30 times higher than the level of BPA that a healthy human is exposed to (Inoue et al., 2000). Because it is critical to elucidate the effects of low doses of BPA in order to evaluate its endocrine-disrupting activities, we investigated whether dopaminergic neurotransmission was affected by prenatal and neonatal exposure to BPA at levels below the lowest-observed- adverse-effect Level. We clearly observed enhancement of the morphine-induced rewarding effects by exposing mice to remarkably low concentrations of BPA (Fig. 2A) (Narita et al., 2006). In addition, the dopamine-induced G-protein activation was also enhanced by prenatal and neonatal ex-

(A)

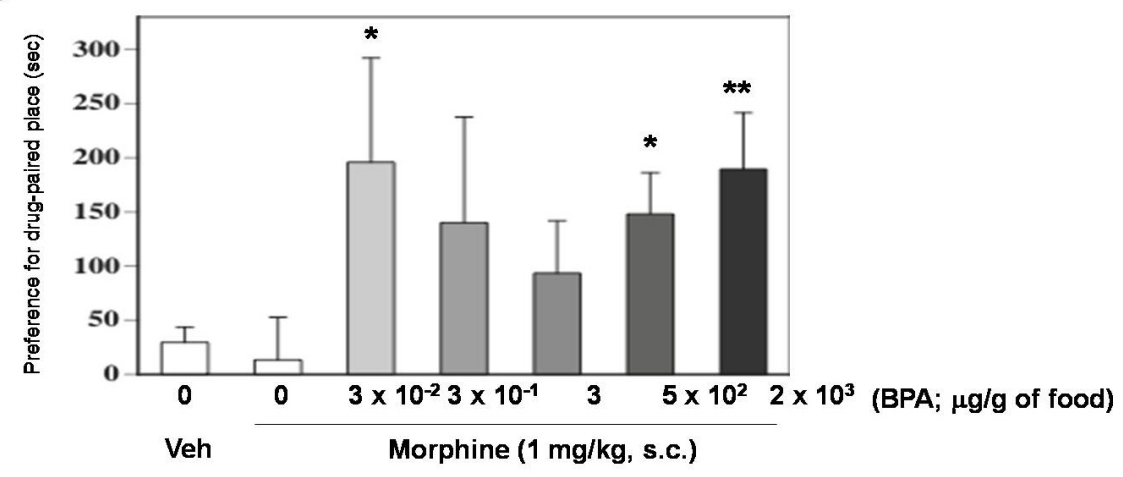

(B)

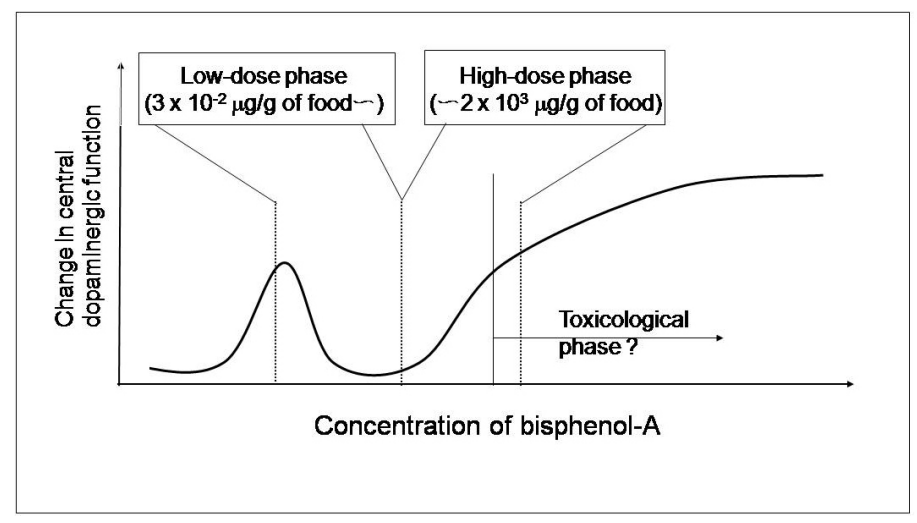

Fig. 2. (A) Effects of prenatal and neonatal exposure to various concentrations of BPA on morphine (1 mg/kg, s.c.)-induced rewarding effects in mice. Each column presents mean \pm SEM conditioning scores of $6-14$ mice $\left({ }^{*} p<0.05,{ }^{* *} p<0.01\right.$ vs. morphinetreated control group). (B) A schematic diagram of the biphasic effect of prenatal and postnatal BPA exposure on central dopaminergic functions. In the previous study, we reported that prenatal and neonatal exposure to high doses $\left(2-2 \times 10^{3} \mu \mathrm{g} / \mathrm{g}\right.$ of food) of BPA alters the central dopaminergic functions. Our present findings suggest that hypersensitivity to morphine-induced pharmacological actions after prenatal and neonatal exposure to low doses $\left(3 \times 10^{-2}\right.$ to $3 \mu \mathrm{g} / \mathrm{g}$ of food) of BPA may be attributable to the upregulation of dopamine receptor functions in the limbic forebrain. [Modified and reproduced from Narita et al., Neurosci. Lett. 402, 249-252. Copyright 2006, with permission from Elsevier.] 
posure to low doses of BPA. Taken together, these findings suggest that the hypersensitivity to morphine-induced pharmacological actions after prenatal and neonatal exposure to low and high doses of BPA may be attributable to the drastic upregulation of dopamine receptor functions in the limbic forebrain (Fig. 2B) (Narita et al., 2006). Therefore, the present findings indicate that prenatal and neonatal exposure to not only high doses but also low doses of BPA may dramatically alter neuronal transmission, including dopaminergic transmission in the adult brain.

Exposure to BPA during either organogenesis or lactation significantly enhanced the morphine-induced rewarding effects (Fig. 3) (Narita et al., 2007) and resulted in the upregulation of dopamine receptor-induced G-protein activation in the mouse limbic forebrain (Narita et al., 2007). In general, during organogenesis of the brain, particularly during cerebral development, it is well known that rapid proliferation, differentiation, or migration of the nerve cells and glial cells occur (Temple, 2001). In addition, the functional development of the CNS occurs most rapidly during lactation (Temple, 2001). Therefore, these results strongly support our present results that organogenesis and lactation are the most sensitive periods during which BPA exposure influences the development of the CNS. Our findings suggest that exposure to BPA during organogenesis could affect differentiation or migration of neuronal stem cells. In addition, exposure to BPA during lactation affects the functional development of the CNS, including synapto-

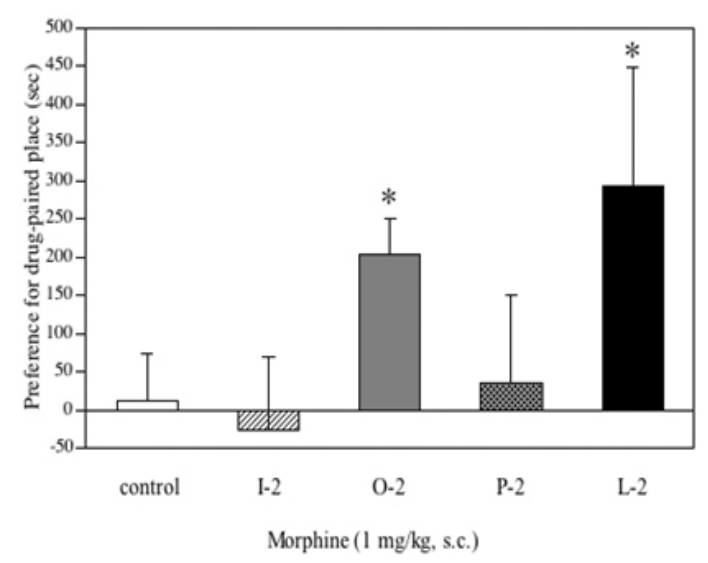

Fig. 3. Enhancement of morphine-induced rewarding effects in mice exposed to BPA during organogenesis or lactation. Mice exposed to BPA in each period are indicated as I-2, O-2, P-2, and L-2 groups (I: implantation, $\mathrm{O}$ : organogenesis, $\mathrm{P}$ : parturition, L: lactation). Each column presents the mean \pm SEM conditioning scores of $6-16$ mice. ( ${ }^{*} p<0.05$ vs. control). [Modified and reproduced from Narita et al., Addict Biol. 12, 167-172. Copyright 2007, with permission from Wiley-Blackwell.] genesis and construction of the neuronal network.

Taken together, the present results may indicate that although BPA treatment of adult animals do not affect reproductive functions and social behaviors, exposure during the prenatal and neonatal stages, especially during organogenesis and lactation, induces toxicity in the developing neurons in the midbrain.

\section{Development of dopaminergic neurons}

Dopaminergic neurons in the mammalian brain have received substantial attention in the past, because they play a fundamental role in several body functions and behaviors. VTA cells modulate reward-related and cognitive behaviors, and their dysfunction is involved in the pathogenesis of addictive disorders and schizophrenia. The precise time of origin of the first postmitotic dopaminergic neurons is a topic of debate. It has become widely accepted that the first dopaminergic neuron originates around embryonic day (ED) 10.5 in mice (Riddle and Pollock, 2003; Smidt et al., 2003). At this time, these cells express Nurr1, a member of the nuclear receptor family, and thus should be considered as postmitotic dopaminergic precursors, because these cells are not completely differentiated dopaminergic neurons (Wallen et al., 1999). In a strict sense, when these precursors start expressing tyrosine hydroxylase $(\mathrm{TH})$, the rate-limiting enzyme for dopamine synthesis, these cells can be considered to be capable of synthesizing dopamine and thus considered as truly dopaminergic neurons. This occurs 1 day after the appearance of the precursor, i.e., at ED11.5, in mice (Wallen et al., 1999). In mice, dopaminergic neurogenesis peaks around ED 12.5 during development and declines thereafter (Bayer et al., 1995; Marti et al., 2002). Migration of the dopaminergic neurons to their final positions in the ventral mesencephalon and innervation in their target sites occur during the first postnatal weeks. In rats, this phase of dopaminergic neuronal development appears to be completed around the third postnatal week (Voorn et al., 1988). At this time, the morphology and functionality of the dopaminergic system are identical to that observed in adults. We have shown that chronic treatment with BPA decreased the expression of dopamine $D_{3}$ receptor, sonic hedgehog (Shh), and glial cell line-derived neurotrophic factor (GDNF) mRNAs in the entire brain obtained from the embryos of mice (ED14) (Miyagawa et al., 2007b). However, no change in the expression levels of these mRNAs was noted in the adult mice after prenatal and neonatal exposure to BPA.

Du et al. (2005) reported that dopamine $D_{3}$ receptor-preferring agonists markedly increased the levels of GDNF 
(A)

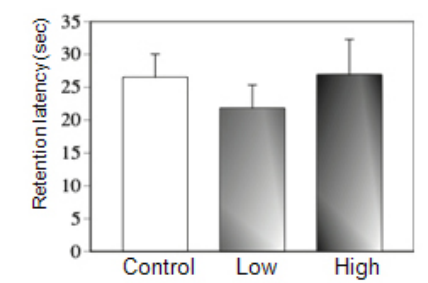

(B)

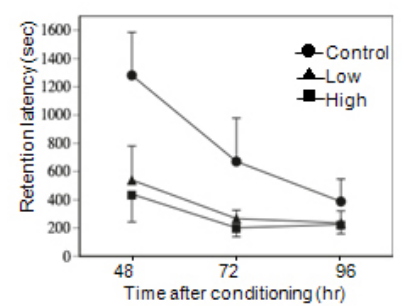

Ci

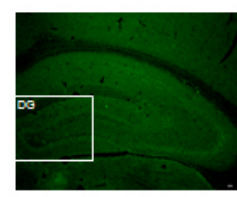

Ciii
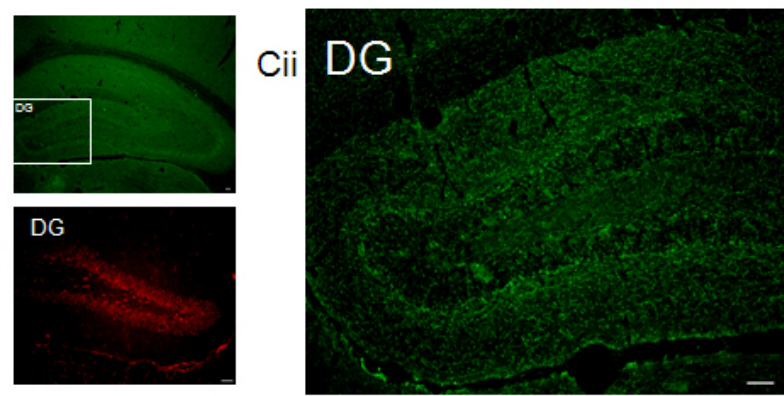

Di

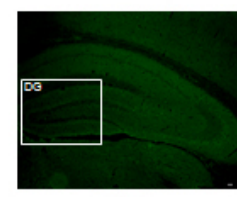

\section{Dii DG}

Diii

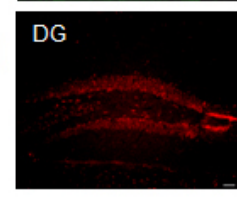

$\mathrm{E}$

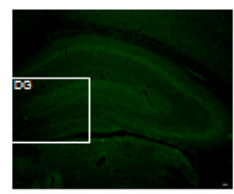

Eiii

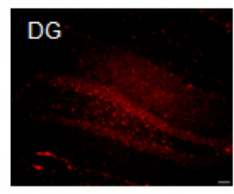

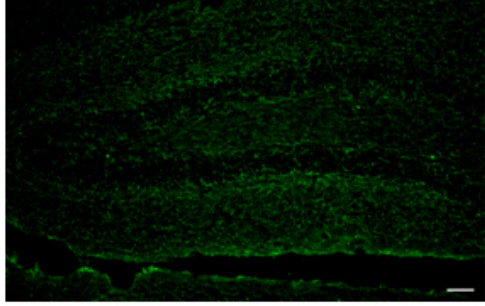

Eii DG

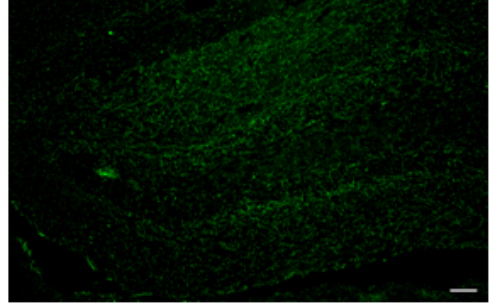

Fig. 4. Effects of prenatal and neonatal exposure to BPA on performance by using a step-through passive avoidance procedure. (A) At conditioning, the mice were placed in the light compartment of a two-compartment box and were administered a foot shock immediately after their entrance in the dark compartment. The step-through latency of the mice that received prenatal and neonatal exposure to low and high doses of BPA was similar to that of the control mice. (B) Prenatal and neonatal exposure to low and high doses of BPA induced significant memory impairment (Low: $\mathrm{F}_{(1,9)}=6.246, p<0.05$ vs. control; High: $\mathrm{F}_{(1,10)}=9.167, p<0.05$ vs. control). Each value represents mean \pm SEM of 5-7 mice. A dramatical reduction in ChAT-like immunoreactivity (IR) but not NeuNlike IR in the hippocampus of the mice that received prenatal and neonatal exposure to low and high doses of BPA ( $\mathrm{Ci}, \mathrm{Di}$, and $\mathrm{Ei})$ was observed. In mice that received prenatal and neonatal exposure to low ( $\mathrm{Di}$ ) and high doses (Ei) of BPA, a dramatic decrease in the level of ChAT-IR was noted in the hippocampus, when compared with the control $(\mathrm{Ci})$. Images of high magnification show ChAT-IR in the dentate gyrus (DG). In the mice that received low (Dii) and high doses (Eii) of prenatal and neonatal exposure to BPA, ChAT-IR was dramatically decreased in the DG, when compared with the control (Cii). On the other hand, in mice exposed to prenatal and neonatal exposure to low (Diii) and high doses (Eiii) of BPA, NeuN-IR in the DG remained unaffected, when compared with the control mice (Aiii). DG: dentate gyrus. Scale bars: $50 \mu \mathrm{m}$. [Modified and reproduced from Miyagawa et al., Neurosci. Lett. 418, 236-241. Copyright 2007, with permission from Elsevier.]

and brain-derived neurotrophic factor (BDNF) in mesencephalic cultures with a conditioned medium; this resulted in an increase in the number of dopaminergic neurons. GDNF is an important neurotrophic factor for the regulation of the development and for the survival of the midbrain dopaminergic neurons (Lin et al., 1993; Kholodilov et al., 2004).

Shh and fibroblast growth factor-8 (FGF-8) have been reported to direct the differentiation of progenitor cells into midbrain dopaminergic neurons (Lee et al., 2000). Shh also plays an important role in dopaminergic axon pathfinding to rostral targets (Hammond et al., 2009)

Therefore, the present results support the idea that pre-

natal and neonatal exposure to BPA may disrupt dopaminergic neuronal development that is associated with Shh and GDNF expressions.

\section{MEMORY IMPAIRMENT OWING TO PRENATAL EXPOSURE TO BPA}

Because the site of action of BPA remains unknown, it is most likely that prenatal and neonatal exposure to BPA induces other behavioral abnormalities associated with the alteration of not only the dopaminergic system but also other neurotransmissions. We investigated the influence of prenatal and neonatal exposure to BPA on memory proc- 
esses in mice by using the step-through passive avoidance test. In the conditioning trial, the step-through latency of the mice exposed to low and high doses of BPA during the prenatal and neonatal stages was similar to that of the control mice (Fig. 4A) (Miyagawa et al., 2007a). Although the step-through latency increased among all the groups as compared to that at conditioning, the latencies of mice that were exposed to BPA during the prenatal and neonatal stages to step into the dark compartment dramatically decreased as compared to those of the control mice. (Fig. 4B) (Miyagawa et al., 2007a). These results strongly suggest that chronic treatment with low and high doses of BPA resulted in memory impairment. Contextual fear conditioning is a hippocampal-dependent memory. Therefore, we subsequently investigated the morphological and/or functional changes in the hippocampus of mice that received prenatal and neonatal exposure to low and high doses of BPA.

Our immunohistochemical examination revealed that in mice that received prenatal and neonatal exposure to low and high doses of BPA, the level of choline acetyltransferase-like immunoreactivity (ChAT-IR) in many regions of the hippocampus dramatically decreased, when compared with the control (Fig. 4Ci-4Ei) (Miyagawa et al., 2007a). In particular, as shown in highly magnified images (Fig. 4Cii-4Eii), the density of the cholinergic fiber was dramatically decreased in mice that received prenatal and neonatal exposure to low and high doses of BPA, when compared with the control (Miyagawa et al., 2007a). It is widely accepted that cholinergic function in the hippocampus is important for learning and memory processes (Bartus et al., 1982; Miyamoto et al., 1987; Dutar et al., 1995). These results strongly support our findings that memory impairment remarkably corresponded to dysfunction of the cholinergic neurons in the hippocampus of mice that received prenatal and neonatal exposure to BPA. On the other hand, in mice that received prenatal and neonatal exposure to BPA, the levels of the neuron-specific nuclear protein (NeuN)-IR in the dentate gyrus (Miyagawa et al., 2007a) and in other regions of the hippocampus remained unaffected, when compared with the control; this finding indicates that prenatal and neonatal exposure to BPA does not result in cell death or layer formation on the mature pyramidal or granular cells in the hippocampus.

\section{ACTIVATION OF ASTROCYTES BY BPA}

There is increasing evidence that astrocytes are important modulators of synaptic transmission. Astrocytes can respond to neurotransmitters released within the syn- aptic cleft by increasing intracellular $\mathrm{Ca}^{2+}$ concentration and releasing glutamate and/or ATP that are signaled back to the neurons (Haydon, 2001; Fellin and Carmignoto, 2004). Therefore, it is worthwhile to determine the effects of BPA on astrocytes. We showed that in vitro treatment with BPA caused morphological changes in glial fibrillary acidic protein (GFAP)-positive astrocytes. (Fig. 5) (Miyatake et al., 2006) In addition, this effect of BPA was biphasic: treatment with $1 \mathrm{pM}$ or $1 \mu \mathrm{M}$ of BPA resulted in robust activation of the astrocytes, whereas treatment with $1 \mathrm{nM}$ of BPA did not have any detectable effects on the morphology of the astrocytes. Treatment with a high concentration of BPA induced marked neuronal cell death in the midbrain neurons/glia cocultures. Thus, these results suggest that a high concentration of BPA may cause dynamic changes in the neuronal-glial network and thus result in neurotoxicity.

Neurons and astrocytes respond to various chemical stimuli, including neurotransmitters, neuromodulators, and hormones, which result in an increase in the intracellular $\mathrm{Ca}^{2+}$ concentration. These $\mathrm{Ca}^{2+}$ responses result from the coordinated activity of several molecular cascades that are involved in the movement of $\mathrm{Ca}^{2+}$ into or out of the cytoplasm from extracellular spaces or intracellular stores, respectively. We reported that treatment with BPA significantly enhanced the dopamine-induced $\mathrm{Ca}^{2+}$ responses in mixed cultures of neurons and astrocytes (Miyatake et al., 2006). These results strongly support the idea that the enhancement of dopamine-induced $\mathrm{Ca}^{2+}$ responses after exposure to BPA could lead to an increase in the excitability of the central dopaminergic neurons.

It has been reported that stimulation of dopamine $D_{1}$ receptor increases intracellular $\mathrm{Ca}^{2+}$ concentration via activation of phospholipase C-inositol-1,4,5-trisphosphate signaling pathway (Pacheco and Jope, 1997; Jin et al., 2003). Dopamine-induced $\mathrm{Ca}^{2+}$ responses are also modulated by dopamine $\mathrm{D}_{2}$ receptor (Zhu et al., 1997; Takeuchi et al., 2002). On the other hand, dopamine $D_{3}$ receptor usually coexists with dopamine $D_{1}$ and $D_{2}$ receptors (Surmeier et al., 1992; Schwartz et al., 1998) and contributes to the inhibitory effects of dopamine $D_{1}$ and/or $D_{2}$ receptor-mediated signaling (Mizuo et al., 2004b). Thus, the present results suggest that treatment with $1 \mathrm{pM}$ of BPA may enhance dopamine $D_{1}$ receptor function and/or attenuate dopamine $D_{3}$ receptor function, resulting in enhancement of the dopamine-induced $\mathrm{Ca}^{2+}$ responses in neurons and astrocytes.

\section{MECHANISMS OF BPA}

With regard to the possible mechanisms of action of 
(A)
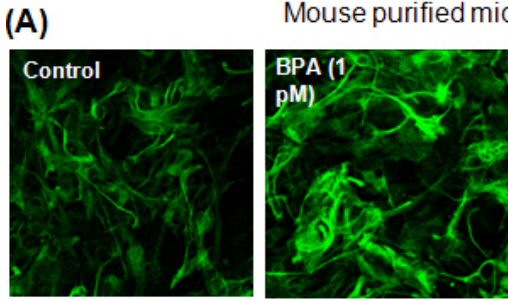

(B)

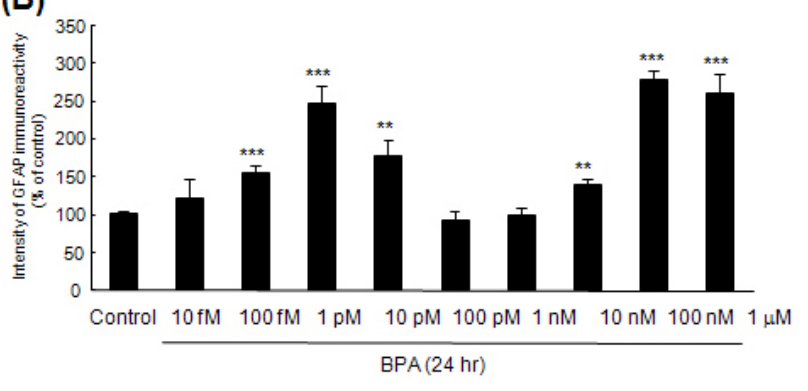

(C)

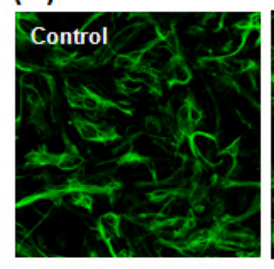

Mouse midbrain neuron/glia co-cultures
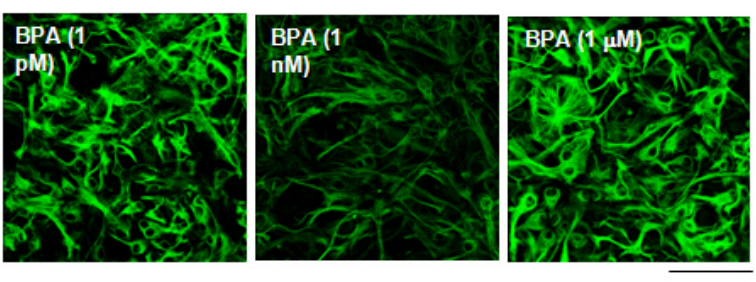

(D)

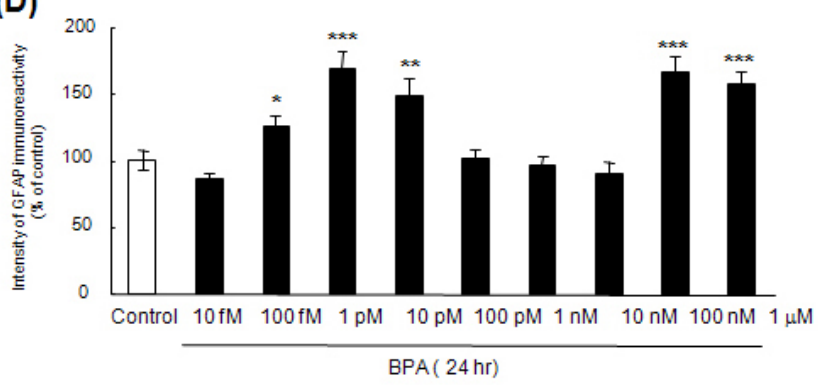

Fig. 5. Treatment with BPA for $24 \mathrm{hr}$ caused biphasic activation of astrocytes in the coculture of purified mouse midbrain astrocytes and neurons/glia. (A) The purified mouse midbrain astrocytes were treated with a normal medium or BPA $(1 \mathrm{pM}-1 \mu \mathrm{M})$. The cells were stained with polyclonal antibodies to GFAP. (B) The purified mouse midbrain astrocytes were treated with a normal medium or BPA (10 fM-1 $\mu \mathrm{M})$ for $24 \mathrm{hr}$ and stained with polyclonal antibodies to GFAP. For each image, the intensity of GFAP-IR in 10 areas was measured using NIH Image. The level of GFAP-like IR is expressed as percentage increase (mean \pm SEM) of that in the control cells. The experiments were repeatedly performed using at least 3 independent culture preparations. $\left({ }^{* *} p<0.001,{ }^{* * *} p<0.001\right.$ vs. control cells.) (C) The cocultures of mouse midbrain neurons/ glia were treated with a normal medium or BPA (1 $\mathrm{pM}-1 \mu \mathrm{M})$. The cells were stained with polyclonal antibodies to GFAP. (D) The cocultures of mouse midbrain neurons/glia were treated with a normal medium or BPA (10 fM-1 $\mu \mathrm{M}$ ) for $24 \mathrm{hr}$ and stained with polyclonal antibodies to GFAP. The intensity of GFAP-IR was measured using $\mathrm{NIH}$ Image. For each image, the level of GFAP-like IR in 10 areas was expressed as percentage increase (mean \pm SEM) of that in the control cells. $\left({ }^{* *} p<0.001,{ }^{* * *} p<0.001\right.$ vs. control cells). The experiments were repeatedly performed using at least 3 independent culture preparations. [Modified and reproduced from Miyatake et al., J. Neuroendocrinol. 18, 434-444. Copyright 2006, with permission from Wiley-Blackwell.]
BPA, it has been reported that BPA has estrogenic activity. The results of recent molecular studies suggest that endogenous estrogen is important for the development of the mammalian brain. It has been suggested estrogen activates transcription of the human dopamine $D_{1}$ receptor gene (Lee and Mouradian, 1999). It can be proposed that upregulation of dopamine $D_{1}$ receptor after prenatal and neonatal exposure to BPA may result from tonic stimulation of estrogen receptors. These findings suggest that the primary action of BPA is to probably mimic or inhibit the endogenous hormone receptor-mediated action, including estrogen receptor-mediated action.

Recently, researchers engaged in molecular studies proposed the rapid signaling of BPA. The rapid signaling of BPA is distinguished from nuclear hormone receptor-mediated transactivation activity that induces gene expression. This rapid signaling pathway can be explained by the involvement of an alternative seven-transmembrane G-protein coupled receptor. GPR30, a G-protein coupled estrogen receptor located in the plasma membrane, is one of the candidate receptors for the rapid signaling of BPA. GPR30 is highly expressed in the hypothalamus, hippocampus, brainstem, and striatum (Brailoiu et al., 2007). Moreover, Brairoiu et al. (2007) reported that a putative GPR30 agonist G-1 rapidly increased intracellular $\mathrm{Ca}^{2+}$ concentration in cultured hypothalamic neurons. We have 
already shown that BPA treatment causes rapid increase in the intracellular $\mathrm{Ca}^{2+}$ concentration in mouse midbrain neurons and glia that were cocultured and in purified astrocytes (Miyatake et al., 2006). Although a detailed mechanism remains to be elucidated, it can be stated that the signaling pathway of GPR30 may, at least in part, contribute to the rapid signaling of BPA.

On the other hand, it was confirmed that BPA exhibited weak estrogenicity; the potency of BPA is approximately 15,000 times lesser than that of $17 \beta$-estradiol (Gaido et al., 1997). Furthermore, BPA binds to estrogen receptors with a low affinity and transactivates the estrogen responsive element-driven reporter gene in vitro (Gaido et al., 1997). We found that antagonists of estrogen receptor, progesterone receptor, and androgen receptor did not have any effect on the BPA-induced activation of astrocytes. Furthermore, treatment with estradiol (E2) did not activate either purified astrocytes or neurons and glia that were cocultured. We also found that prenatal and postnatal exposure to E2 failed to enhance the rewarding effects of morphine in mice. These results suggest that estrogen is not essential for the enhancement of dopaminergic neurotransmission and the BPA-induced hypersensitivity to morphine-induced rewarding effects.

Some of the other mechanisms for BPA have been proposed. BPA has been reported to act as an antagonist of thyroid receptors (Moriyama et al., 2002). It is widely known that thyroid hormones are essential for brain development. In addition, Song et al. (2002) reported that BPA induces the orphan nuclear receptor Nur77 gene expression and is involved in steroidogenesis in the Leydig cells of mice. Several subfamilies of Nur77, for example, NGFI-B or Nurr1, have been shown to be highly expressed in the brain (Xiao et al., 1996). In particular, it has been accepted that NGFI-B is highly expressed in the basal ganglia and is involved in the development of dopaminergic and opioidergic systems (Zetterstrom et al., 1996).

Several findings indicate that BPA induces oxidative stress in many organs (Bindhumol et al., 2003; Kabuto et al., 2003). BPA facilitates the production of reactive oxygen species (ROS) and thus results in neuronal damage (Ooe et al., 2005; Lee et al., 2008). Moreover, BPA and some bisphenols have been reported to cause a reduction in mitochondrial functions (Nakagawa and Tayama, 2000). It is widely accepted that during development, neurons are highly sensitive to ROS. Although further studies are needed to clarify the effects of BPA on the developmental processes, the findings of these reports suggest that oxidative stress may contribute to the action of BPA.

Finally, the findings of recent studies suggest that BPA appears to induce physiological responses such as DNA methylation via epigenetic mechanisms (Ho et al., 2006; Dolinoy et al., 2007; Yaoi et al., 2008; Baccarelli and Bollati, 2009; Bromer et al., 2010). Ho et al. (2006) reported that neonatal exposure to BPA increases phosphodiesterase-4 expression, which results from early and increased DNA hypomethylation. Yaoi et al. (2008) showed that exposure to low doses of BPA alters DNA methylation in the forebrain of a mouse fetus.

Taken together, these findings suggest that although we cannot completely exclude the possibility of the estrogenic action of BPA, the action of BPA that is currently known may mainly be attributable to novel mechanisms underlying dopaminergic transmission.

\section{CONCLUSION}

In this review article, we provide evidences to support the idea that prenatal and neonatal exposure to various concentrations of BPA could affect various stages of neuronal development. Research regarding the biological effects of BPA has tremendously progressed in the last decade. We hope that the findings of these studies will elucidate the complete mechanisms of BPA in the future.

\section{ACKNOWLEDGMENTS}

This work was supported, in part, by grants from the Ministry of Health, Labour and Welfare, and the Ministry of Education, Culture, Sports, Science and Technology of Japan.

\section{REFERENCES}

Baccarelli, A. and Bollati, V. (2009). Epigenetics and environmental chemicals. Curr. Opin. Pediatr. 21, 243-251.

Bardo, M. T. (1998). Neuropharmacological mechanisms of drug reward: beyond dopamine in the nucleus accumbens. Crit. Rev. Neurobiol. 12, 37-67.

Bartus, R. T., Dean, R. L. 3rd, Beer, B. and Lippa, A. S. (1982). The cholinergic hypothesis of geriatric memory dysfunction. Science 217, 408-414.

Bayer, S. A., Wills, K. V., Triarhou, L. C. and Ghetti, B. (1995). Time of neuron origin and gradients of neurogenesis in midbrain dopaminergic neurons in the mouse. Exp. Brain Res. 105, 191-199.

Bindhumol, V., Chitra, K. C. and Mathur, P. P. (2003). Bisphenol $A$ induces reactive oxygen species generation in the liver of male rats. Toxicology 188, 117-124.

Brailoiu, E., Dun, S. L., Brailoiu, G. C., Mizuo, K., Sklar, L. A., Oprea, T. I., Prossnitz, E. R. and Dun, N. J. (2007). Distribution and characterization of estrogen receptor $\mathrm{G}$ proteincoupled receptor 30 in the rat central nervous system. $J$. 
Endocrinol. 193, 311-321.

Bromer, J. G., Zhou, Y., Taylor, M. B., Doherty, L. and Taylor, H. S. (2010). Bisphenol-A exposure in utero leads to epigenetic alterations in the developmental programming of uterine estrogen response. FASEB J. 24 (published online Feb 24)

Devoto, P., Collu, M., Muntoni, A. L., Pistis, M., Serra, G., Gessa, G. L. and Diana, M. (1995). Biochemical and electrophysiological effects of 7-OH-DPAT on the mesolimbic dopaminergic system. Synapse 20, 153-155.

Dolinoy, D. C., Huang, D. and Jirtle, R. L. (2007). Maternal nutrient supplementation counteracts bisphenol A-induced DNA hypomethylation in early development. Proc. Natl. Acad. Sci. U. S. A. 104, 13056-13061.

Dutar, P., Bassant, M. H., Senut, M. C. and Lamour, Y. (1995). The septohippocampal pathway: structure and function of a central cholinergic system. Physiol. Rev. 75, 393-427.

Farabollini, F., Porrini, S., Della Seta, D., Bianchi, F. and DessiFulgheri, F. (2002). Effects of perinatal exposure to bisphenol A on sociosexual behavior of female and male rats. Environ. Health Perspect. 110 (Suppl 3), 409-414.

Fellin, T. and Carmignoto, G. (2004). Neurone-to-astrocyte signalling in the brain represents a distinct multifunctional unit. J. Physiol. 559, 3-15.

Gaido, K. W., Leonard, L. S., Lovell, S., Gould, J. C., Babai, D., Portier, C. J. and McDonnell, D. P. (1997). Evaluation of chemicals with endocrine modulating activity in a yeast-based steroid hormone receptor gene transcription assay. Toxicol. Appl. Pharmacol. 143, 205-212.

Hammond, R., Blaess, S. and Abeliovich, A. (2009). Sonic hedgehog is a chemoattractant for midbrain dopaminergic axons. PLoS One 4, e7007.

Haydon, P. G. (2001). GLIA: listening and talking to the synapse. Nat. Rev. Neurosci. 2, 185-193.

Ho, S. M., Tang, W. Y., Belmonte de Frausto, J. and Prins, G. S. (2006). Developmental exposure to estradiol and bisphenol A increases susceptibility to prostate carcinogenesis and epigenetically regulates phosphodiesterase type 4 variant 4 . Cancer Res. 66, 5624-5632.

Howdeshell, K. L., Hotchkiss, A. K., Thayer, K. A., Vandenbergh, J. G. and vom Saal, F. S. (1999). Exposure to bisphenol A advances puberty. Nature 401, 763-764.

Inoue, K., Kato, K., Yoshimura, Y., Makino, T. and Nakazawa, H. (2000). Determination of bisphenol A in human serum by high-performance liquid chromatography with multi-electrode electrochemical detection. J. Chromatogr. B. Biomed. Sci. Appl. 749, 17-23.

Jin, L. Q., Goswami, S., Cai, G., Zhen, X. and Friedman, E. (2003). SKF83959 selectively regulates phosphatidylinositollinked $D_{1}$ dopamine receptors in rat brain. J. Neurochem. $\mathbf{8 5}$ 378-386.

Kabuto, H., Hasuike, S., Minagawa, N. and Shishibori, T. (2003). Effects of bisphenol A on the metabolisms of active oxygen species in mouse tissues. Environ. Res. 93, 31-35.

Kholodilov, N., Yarygina, O., Oo, T. F., Zhang, H., Sulzer, D., Dauer, W. and Burke, R. E. (2004). Regulation of the development of mesencephalic dopaminergic systems by the selective expression of glial cell line-derived neurotrophic factor in their targets. J. Neurosci. 24, 3136-3146.

Koeltzow, T. E., Xu, M., Cooper, D. C., Hu, X. T., Tonegawa, S., Wolf, M. E. and White, F. J. (1998). Alterations in dopamine release but not dopamine autoreceptor function in dopamine $\mathrm{D}_{3}$ receptor mutant mice. J. Neurosci. 18, 2231-2238.

Koob, G. F. (1992). Drugs of abuse: anatomy, pharmacology and function of reward pathways. Trends Pharmacol. Sci. $13,177-184$

Kubo, K., Arai, O., Ogata, R., Omura, M., Hori, T. and Aou, S. (2001). Exposure to bisphenol A during the fetal and suckling periods disrupts sexual differentiation of the locus coeruleus and of behavior in the rat. Neurosci. Lett. 304, 73-76.

Lee, S., Suk, K., Kim, I. K., Jang, I. S., Park, J. W., Johnson, V. J., Kwon, T. K., Choi, B. J. and Kim, S. H. (2008). Signaling pathways of bisphenol A-induced apoptosis in hippocampal neuronal cells: role of calcium-induced reactive oxygen species, mitogen-activated protein kinases, and nuclear factorkappaB. J. Neurosci. Res. 86, 2932-2942.

Lee, S. H., Lumelsky, N., Studer, L., Auerbach, J. M. and McKay, R. D. (2000). Efficient generation of midbrain and hindbrain neurons from mouse embryonic stem cells. Nat. Biotechnol. 18, 675-679.

Lee, S. H. and Mouradian, M. M. (1999). Up-regulation of $D_{1 A}$ dopamine receptor gene transcription by estrogen. Mol. Cell. Endocrinol. 156, 151-157.

Levant, $B$. (1997). The $D_{3}$ dopamine receptor: neurobiology and potential clinical relevance. Pharmacol. Rev. 49, 231-252.

Lin, L. F., Doherty, D. H., Lile, J. D., Bektesh, S. and Collins, F. (1993). GDNF: a glial cell line-derived neurotrophic factor for midbrain dopaminergic neurons. Science 260, 1130-1132.

Marti, J., Wills, K. V., Ghetti, B. and Bayer, S. A. (2002). A combined immunohistochemical and autoradiographic method to detect midbrain dopaminergic neurons and determine their time of origin. Brain. Res. Brain. Res. Protoc. 9, 197-205.

Miyagawa, K., Narita, M., Akama, H. and Suzuki, T. (2007a). Memory impairment associated with a dysfunction of the hippocampal cholinergic system induced by prenatal and neonatal exposures to bisphenol-A. Neurosci. Lett. 418 , 236-241.

Miyagawa, K., Narita, M., Niikura, K., Akama, H., Tsurukawa, Y. and Suzuki, T. (2007b). Changes in central dopaminergic systems with the expression of Shh or GDNF in mice perinatally exposed to bisphenol-A. Nihon Shinkei Seishin Yakurigaku Zasshi 27, 69-75.

Miyamoto, M., Kato, J., Narumi, S. and Nagaoka, A. (1987). Characteristics of memory impairment following lesioning of the basal forebrain and medial septal nucleus in rats. Brain Res. 419, 19-31.

Miyatake, M., Miyagawa, K., Mizuo, K., Narita, M. and Suzuki, T. (2006). Dynamic changes in dopaminergic neurotransmission induced by a low concentration of bisphenol-A in neurones and astrocytes. J. Neuroendocrinol. 18, 434-444.

Mizuo, K., Narita, M., Miyagawa, K., Okuno, E. and Suzuki, T. (2004a). Prenatal and neonatal exposure to bisphenol-A affects the morphine-induced rewarding effect and hyperlocomotion in mice. Neurosci. Lett. 356, 95-98.

Mizuo, K., Narita, M., Miyatake, M. and Suzuki, T. (2004b). Enhancement of dopamine-induced signaling responses in the forebrain of mice lacking dopamine $D_{3}$ receptor. Neurosci. Lett. 358, 13-16.

Mizuo, K., Narita, M., Yoshida, T. and Suzuki, T. (2004c). Functional changes in dopamine $D_{3}$ receptors by prenatal and neonatal exposure to an endocrine disruptor bisphenol-A 
in mice. Addict Biol. 9, 19-25.

Moriyama, K., Tagami, T., Akamizu, T., Usui, T., Saijo, M., Kanamoto, N., Hataya, Y., Shimatsu, A., Kuzuya, H. and Nakao, K. (2002). Thyroid hormone action is disrupted by bisphenol A as an antagonist. J. Clin. Endocrinol. Metab. 87, 5185-5190.

Nakagawa, Y. and Tayama, S. (2000). Metabolism and cytotoxicity of bisphenol $A$ and other bisphenols in isolated rat hepatocytes. Arch. Toxicol. 74, 99-105.

Narita, M., Funada, M. and Suzuki, T. (2001). Regulations of opioid dependence by opioid receptor types. Pharmacol. Ther. 89, 1-15.

Narita, M., Miyagawa, K., Mizuo, K., Yoshida, T. and Suzuki, T. (2006). Prenatal and neonatal exposure to low-dose of bisphenol-A enhance the morphine-induced hyperlocomotion and rewarding effect. Neurosci. Lett. 402, 249-252.

Narita, M., Miyagawa, K., Mizuo, K., Yoshida, T. and Suzuki, T. (2007). Changes in central dopaminergic systems and morphine reward by prenatal and neonatal exposure to bisphenol-A in mice: evidence for the importance of exposure period. Addict Biol. 12, 167-172.

Narita, M., Mizuo, K., Mizoguchi, H., Sakata, M., Tseng, L. F. and Suzuki, T. (2003). Molecular evidence for the functional role of dopamine $D_{3}$ receptor in the morphine-induced rewarding effect and hyperlocomotion. J. Neurosci. 23, 1006-1012.

Ooe, H., Taira, T., Iguchi-Ariga, S. M. and Ariga, H. (2005). Induction of reactive oxygen species by bisphenol $A$ and abrogation of bisphenol A-induced cell injury by DJ-1. Toxicol. Sci. 88, 114-126.

Pacheco, M. A. and Jope, R. S. (1997). Comparison of $\left[{ }^{3} \mathrm{H}\right]$ phosphatidylinositol and $\left[{ }^{3} \mathrm{H}\right.$ ] phosphatidylinositol 4,5-bisphosphate hydrolysis in postmortem human brain membranes and characterization of stimulation by dopamine D1 receptors. J. Neurochem. 69, 639-644.

Riddle, R. and Pollock, J. D. (2003). Making connections: the development of mesencephalic dopaminergic neurons. Brain Res. Dev. Brain Res. 147, 3-21.

Schwartz, J. C., Diaz, J., Bordet, R., Griffon, N., Perachon, S., Pilon, C., Ridray, S. and Sokoloff, P. (1998). Functional implications of multiple dopamine receptor subtypes: the $\mathrm{D}_{1} / \mathrm{D}_{3}$ receptor coexistence. Brain Res. Brain Res. Rev. 26 236-242.

Sigmundson, H. K. (1994). Pharmacotherapy of schizophrenia: a review. Can. J. Psychiatry 39, S70-75.

Smidt, M. P., Smits, S. M. and Burbach, J. P. (2003). Molecular mechanisms underlying midbrain dopamine neuron development and function. Eur. J. Pharmacol. 480, 75-88.

Sokoloff, P., Giros, B., Martres, M. P., Bouthenet, M. L. and
Schwartz, J. C. (1990). Molecular cloning and characterization of a novel dopamine receptor $\left(D_{3}\right)$ as a target for neuroleptics. Nature 347, 146-151.

Surmeier, D. J., Eberwine, J., Wilson, C. J., Cao, Y., Stefani, A. and Kitai, S. T. (1992). Dopamine receptor subtypes colocalize in rat striatonigral neurons. Proc. Natl. Acad. Sci. U. S. A. 89, 10178-10182.

Suzuki, T. (1996). Conditioned place preference in mice. Meth. Find. Exp. Clin. Pharmacol. 18, 75-83.

Suzuki, T., Mizuo, K., Nakazawa, H., Funae, Y., Fushiki, S. Fukushima, S., Shirai, T. and Narita, M. (2003). Prenatal and neonatal exposure to bisphenol-A enhances the central dopamine $D_{1}$ receptor-mediated action in mice: enhancement of the methamphetamine-induced abuse state. Neuroscience 117, 639-644.

Takeuchi, Y., Fukunaga, K. and Miyamoto, E. (2002). Activation of nuclear $\mathrm{Ca}^{2+} /$ calmodulin-dependent protein kinase II and brain-derived neurotrophic factor gene expression by stimulation of dopamine D2 receptor in transfected NG10815 cells. J. Neurochem. 82, 316-328.

Temple, S. (2001). The development of neural stem cells. Nature 414, 112-117.

Voorn, P., Kalsbeek, A., Jorritsma-Byham, B. and Groenewegen, H. J. (1988). The pre- and postnatal development of the dopaminergic cell groups in the ventral mesencephalon and the dopaminergic innervation of the striatum of the rat. Neuroscience 25, 857-887.

Wallen, A., Zetterstrom, R. H., Solomin, L., Arvidsson, M., Olson, L. and Perlmann, T. (1999). Fate of mesencephalic AHD2-expressing dopamine progenitor cells in NURR1 mutant mice. Exp. Cell Res. 253, 737-746.

Xiao, Q., Castillo, S. O. and Nikodem, V. M. (1996). Distribution of messenger RNAs for the orphan nuclear receptors Nurr1 and Nur77 (NGFI-B) in adult rat brain using in situ hybridization. Neuroscience 75, 221-230.

Yaoi, T., Itoh, K., Nakamura, K., Ogi, H., Fujiwara, Y. and Fushiki S. (2008). Genome-wide analysis of epigenomic alterations in fetal mouse forebrain after exposure to low doses of bisphenol A. Biochem. Biophys. Res. Commun. 376, 563567.

Zetterstrom, R. H., Solomin, L., Mitsiadis, T., Olson, L. and Perlmann, T. (1996). Retinoid X receptor heterodimerization and developmental expression distinguish the orphan nuclear receptors NGFI-B, Nurr1, and Nor1. Mol. Endocrinol. 10, $1656-1666$.

Zhu, W. H., Conforti, L. and Millhorn, D. E. (1997). Expression of dopamine $D_{2}$ receptor in PC-12 cells and regulation of membrane conductances by dopamine. Am. J. Physiol. 273 C1143-1150. 